\title{
Awareness and Attitude towards Functional Dairy Products among Consumers in Western Province of Sri Lanka
}

\author{
N.M. Nayana Kumari Narayana ${ }^{1, a, *}$, W. Sanjeewa K. Fernando ${ }^{1, b}$, G. Chandima Samaraweera ${ }^{2, c}$ \\ ${ }^{1}$ Department of Animal Science, Faculty of Agriculture, University of Ruhuna, Mapalana, Kamburupitiya, Sri Lanka \\ ${ }^{2}$ Department of Agricultural Economics, Faculty of Agriculture, University of Ruhuna, Mapalana, Kamburupitiya, Sri Lanka
}

*Corresponding author

A R T I C LE INFO A B S T R A C T

Research Article

Functional foods are the foods that provide health benefits beyond basic nutrition. Dairy products have a prominent position in the functional food market. However, the market share for functional dairy products in Sri Lanka is low compared to most of the countries in the world. Therefore, a study was conducted to investigate the status of awareness of and attitudes towards functional dairy products among consumers from the Western Province of Sri Lanka. The study was conducted using a pre-tested structured questionnaire during June to November 2018, with the participation of 307 purposively selected consumers. Information on consumers' tendency towards a healthy lifestyle, awareness, and perception of health benefits of functional foods and dairy products, confidence in different information sources etc. were recorded. SPSS statistical software package was used for the data analysis. The empirical findings showed that consumers still concern about taste and cost rather

Keywords: than health when buying food products. Consumer age showed a significant and a positive association with a tendency towards a healthy lifestyle. Knowledge and awareness of functional dairy products, functional ingredients, and their benefits are considerably low among the consumers. However, consumer education showed a significant positive associations with the knowledge and awareness and knowledge of the ingredients present in functional foods and dairy products. Information availability, trustfulness, and media advertising had a significant effect on increasing consumer knowledge. Participants predominantly received information through electronic media $(97.7 \%)$. Powdered milk followed by ice-cream and yogurt was requested by the consumers to be developed as future functional dairy products. A majority $(70.7 \%)$ of the consumers did not satisfy with the existing market access and availability of variants and therefore, a good potential exists for the introduction of novel functional dairy products to the functional food market of Sri Lanka.

Attitude

Health benefits

Healthy lifestyle

\section{Introduction}

Foods are not only intended to satisfy hunger and to provide necessary nutrients but also to prevent nutritionrelated diseases and to improve the physical and mental well-being of the consumers (Menrad, 2003; Roberfroid, 2002; Azzurra and Paola, 2009). There is a tendency of current consumers turning to healthy diets from luxury diets. Consumer interest in the health benefits of foods and food components is at an all-time high and will continue to grow (Hasler and Brown, 2009). As mentioned by Mohamad et al., (2014) concerning organic food consumption, functional food (FF) products consumption as well, is on the rise among consumers all over the world due to increasing health consciousness. Functional foods are an exciting trend in the food and nutrition field. The concept was first introduced by Japanese scientists in 1984 to establish the link between nutrition, sensory satisfaction, fortification and modulation of physiological systems (Siro et al., 2008). In Japan, those foods have been marketed as "Foods for Specified Health Use" (FOSHU).

The definition of FFs is a confrontational issue because it is agreed that all foods are already functional at some physiological level. But according to the American Dietetic Association, FFs include whole foods and fortified, enriched or enhanced foods that have a potentially beneficial effect on health when consumed as part of a varied diet regularly, at effective levels (Hasler and Brown, 2009). The International Food Information Council defines FFs as "foods and food components that may provide benefits beyond basic nutrition" (IFIC, 2011). According to the Institute of Food Technologists, FFs are 
defined as "Foods and food components that provide a health benefit beyond basic nutrition (for the intended population). Functional foods provide essential nutrients often beyond quantities necessary for normal maintenance, growth, and development, and/or other biologically active components that impart health benefits or desirable physiological effects. Functional foods may include, for example, naturally occurring components of fruits and vegetables, whole grains and fiber in certain breads and cereals, calcium in milk, and fortified foods and beverages, such as vitamin D fortified milk (IFT, 2017). According to the World Health Organization (WHO) report on ageing and health (WHO, 2015), 56.4 million global deaths were reported in 2014 and out of that, 39.5 million or $70 \%$ were due to non-communicable diseases (NCDs). The four main NCDs are cardiovascular diseases, cancers, diabetes and chronic lung diseases and about $48 \%$ of deaths are occurring before the age of 70 years. Functional food products are being examined intensively for added physiological benefits, which may reduce NCDs or otherwise optimize health.

The agro-food companies have responded to the healthy eating trend of the consumers which has surged the demand of FFs across the globe, and have developed a variety of new products to meet the consumer demand. It was estimated and reported that the global FF market size was at USD 161.49 billion in the year 2018 (Grand View Research, 2019). Even though food and nutrition science has moved from identifying and correcting nutritional deficiencies to design foods that promote optimal health and reduce the risk of diseases, regulatory policies must ensure the safety and efficacy of products and the accuracy of their marketing claims to be succeeded in the current competitive market with health-conscious and knowledgeable consumers.

The future of the FF market strongly depends on the consumer awareness and acceptance of these foods since the success of any product depends on the consumer acceptability. Therefore, it is important to understand consumer knowledge and awareness, behaviour, attitude, and perception about FFs to develop the products accordingly. Ares and Gambaro (2007) investigated the interaction between carrier and enrichment of the carrier in FF development and consumer purchasing intention. They have shown that there is a significant role of carriers in determining consumers' purchasing intentions of FFs. Some carriers obviously perceived as healthy while others are not. Those healthy carriers are easily accepted by the consumers as compared to unhealthy ones. Consumers consider milk and milk products as healthy carriers. In that sense, dairy products can be considered as one of the best carriers that can be developed into FFs. A large number of functional dairy products (FDPs) already exists in the current market all over the world such as probiotic, prebiotic and symbiotic added, vitamin, mineral, and fibre fortified, omega 3 fatty acid incorporated, antioxidant added, etc. It has been reported that in Europe, dairy products are the major contributors in the FF market by contributing approximately $60 \%$ of the FF spellings. The Australian FF market is in its early life and is presently expected at $\$ 57$ million where probiotic yogurt is being the head in this zone (Gasmalla et al., 2017).
Even though the global market for FFs is remarkably at a high level with expanding trend, the market share for healthy foods including FDPs in Sri Lanka is yet in infancy. A better understanding of consumers' knowledge and awareness, behaviour, attitude, and perception are key factors for the market success of FFs including FDPs. This research aim at finding the knowledge, behaviour, and attitude among Sri Lankan consumers towards healthy dairy products with particular reference to FDPs in order to derive indications that may contribute innovative product development and marketing decisions to maximize the satisfaction of health-conscious consumers.

\section{Materials and Methods}

\section{Study Area}

Western Province, which is the first level administrative division of Sri Lanka, was selected as the study area. It is the most densely populated province in the country and the nation's business center. Population of the Western Province was reported as 5,821,710 in 2012 (DCS, 2011). The province consists of Colombo, Gampaha and Kalutara Districts where different communities belong to different cultures are residing.

\section{Population, Sampling and Data Collection}

A total of 307 consumers (over 18 years old and regular dairy product consumers having good health) from Colombo $(n=104)$, Gampaha $(n=103)$ and Kaluthara $(n=100)$ Districts of Western Province of Sri Lanka were selected using a purposive sampling method. Primary data were obtained through pre-tested (using 30 consumers) comprehensive structured type questionnaire using face to face interviews from June to November 2018. Information on several aspects was collected; specifically, consumer's tendency towards a healthy life-style, knowledge, and awareness about functional foods especially FDPs, consumer perception on health benefits of functional foods and FDPs, confidence in different sources that gives information on FDPs, etc. Secondary data were obtained from published journals, articles and web sources.

\section{Data Analysis}

Inferential data analysis was done using a Two-step cluster analysis, Chi-square test, and Wilcoxon signedrank test by using IBM SPSS Statistical software package (version 20.0). Descriptive data analysis was done by using bar charts and graphs in MS Excel 2013.

\section{Results and Discussion}

\section{Demographic Characteristics of the Participants}

Table 1 presents the demographic characteristics of the consumers participated in the present study. Consumers were more or less equally distributed among the 3 districts of the Western Province of Sri Lanka i.e. 33.9\% of the consumers were from Colombo District followed by Gampaha (33.6\%) and Kalutara (32.6\%).

It was observed that, out of the total respondents, $46.9 \%$ were males and $53.1 \%$ were females. Further, $34.9 \%$ of consumers were in the age range of $18-30,36.8 \%$ were between $31-40,19.5 \%$ were between $41-50$ and the rest of the consumers were 51 years and above. A majority 
$(63.5 \%)$ of the consumers were married while the others $(36.5 \%)$ were single. From the surveyed respondents, $22.1 \%$ were engaged in the government sector wage employment while $30.9 \%$ were engaged in the private sector. Housewives comprised of $20.5 \%$ of the sample, $13 \%$ were students and the rest of the consumers were in the unemployed group. Among the consumers, 28.3\% mentioned that they did not have any income. It was observed that this group consisted mainly of housewives, students, and the unemployed group. A majority (70.6\%) of the consumers' earnings was less than Rs. 50,000 per month and only $5 \%$ of the consumers were having earnings of more than Rs. 75,000 per month. Further, it was noted that the majority $(63.5 \%)$ of the consumers had at least GCE Advanced Level or above educational qualifications.

Table 1. Demographic variables of the participants $(n=307)$

\begin{tabular}{|c|c|c|}
\hline Item & Total (n) & Percentage $(\%)$ \\
\hline \multicolumn{3}{|c|}{ District } \\
\hline Colombo & 104 & 33.9 \\
\hline Gampaha & 103 & 33.6 \\
\hline Kalutara & 100 & 32.6 \\
\hline \multicolumn{3}{|c|}{ Sex } \\
\hline Male & 144 & 46.9 \\
\hline Female & 163 & 53.1 \\
\hline \multicolumn{3}{|c|}{ Age category } \\
\hline $18-30 \mathrm{y}$ & 107 & 34.9 \\
\hline $31-40 \mathrm{y}$ & 113 & 36.8 \\
\hline $41-50 \mathrm{y}$ & 60 & 19.5 \\
\hline$\geq 51 \mathrm{y}$ & 27 & 8.8 \\
\hline \multicolumn{3}{|c|}{ Marital status } \\
\hline Married & 195 & 63 \\
\hline Single & 112 & 36.5 \\
\hline \multicolumn{3}{|c|}{ Occupation } \\
\hline Government sector & 68 & 22.3 \\
\hline Private sector & 95 & 30.9 \\
\hline Housewife & 63 & 20.5 \\
\hline Student & 40 & 13.0 \\
\hline Unemployed & 5 & 1.6 \\
\hline Other & 36 & 11.7 \\
\hline \multicolumn{3}{|c|}{ Income (LKR) } \\
\hline$<25,000$ & 115 & 37.4 \\
\hline 25,000 to 50,000 & 102 & 33.2 \\
\hline 50,000 to 75,000 & 75 & 24.4 \\
\hline$>75,000$ & 15 & 5 \\
\hline \multicolumn{3}{|c|}{ Education level } \\
\hline Primary & 29 & 9.4 \\
\hline Ordinary level & 83 & 27 \\
\hline Advanced level & 131 & 42.7 \\
\hline Degree & 64 & 20.8 \\
\hline
\end{tabular}

\section{Consumers' Tendency Towards a Healthy Lifestyle}

\section{Food choice motives of the consumers}

According to the theory of planned behavior, human food choice is a complex phenomenon influenced by a wide range of factors. A lot of the determinants of food choice are expected to be mediated by the beliefs and attitudes apprehended by an individual (Jain et al., 2013). A majority (37\%) of the consumers in the Western Province of Sri Lanka consider taste as the most important food choice mortive, rather than cost (32\%) in purchasing foods, followed by health $(30 \%)$ and nutrition $(1 \%)$. This indicates that even though the NCDs due mainly to unacceptable dietary patterns and lack of exercises is the leading cause of death among Sri Lankans (Jayawardena, 2018), consumers still concern about the taste and the cost of products rather than health when selecting and purchasing food products including FDPs.
A similar study conducted in India by Jain et al. (2013) showed also that taste is the most important factor affecting FF choice followed by nutrition, convenience, and cost. A study conducted by Jayasuriya (2016) on Sri Lankan consumers' attitudes towards healthy meals also reported that unless otherwise having a critical health issue, Sri Lankans do not purchase foods which are less in taste and therefore, if a vendor focuses only on healthiness of a meal, there would be a risk of market failure. A study conducted in Italy by Azzurra and Paola (2009) on organic and FFs also mentioned that consumers consider taste as the most important attribute in food choice followed by nutritional aspects while freshness, price, and brand are perceived as mildly important attributes. In another study conducted in Italy by Annunziata and Vecchio (2011) on factors affecting Italian consumer's attitudes towards FFs found 
that despite being aware of the close connection between diet and health, the consumers were not willing to forget the pleasure of what they eat. A study conducted in Pakistan (Ali and Rahut, 2019) on healthy food consumption as a proxy for FFs showed that consumers with ill health were more eager to consume FFs compared to healthier people. Further, Naughton et al. (2015) reported that people with weak healthy eating attitude choose foods that are tastier than healthy. This implies that the food researchers and manufacturers are needed to pay much attention to develop future FFs with satisfactory taste appeal along with health aspects.

Consumers' opinion on doing exercises for a healthy life

Not only healthy food consumption, but exercises also play a significant role in deciding the healthy life of a person. Inactivity is as much of a health risk as smoking (WCRF, 2007). Regular exercises are necessary for physical fitness and good health and it is well documented that it reduces the risk of heart disease, cancer, high blood pressure, diabetes, and other NCDs. In the current study, consumers were categorized using two-step cluster analysis, into 5 clusters based on their opinion on doing exercises for a healthy life (Figure 1). Nearly half (49.9\%) of the consumers mentioned that they do the exercises regularly, while the rest $(50.2 \%)$ do not.

The consumers who do the exercises regularly were categorized further according to their opinion on doing exercises for a healthy life. Out of those consumers $52.3 \%$ mentioned that the exercises are essential for a healthy life and $47.7 \%$ mentioned that exercises are needful for a healthy life. The other $50.2 \%$ of the consumers mentioned that they do not do exercises on a regular basis. However, among them, the majority of the consumers were in the opinion that exercises are essential $(42.2 \%)$ and needful (29.2\%) for a healthy life. Only $28.5 \%$ of the consumers mentioned that the exercises are not needed and the diet is adequate to maintain a healthy life. A study on the "Assessment of the knowledge and perception of high school students towards FFs" conducted in Turkey by Kendilci et al. (2017) has mentioned that $57.8 \%$ of the students surveyed stated that the exercises had a great role in maintaining a healthy life.

Consumers' knowledge on the relationship between diet and health and its reflection in purchasing behaviour of food products

Figure 2 has been derived by clustering the consumers based on their knowledge on the relationship between diet and health as well as its reflection in their buying/consuming behaviour of food products. Cluster 1 $(64.5 \%)$ represents the consumers who had a clear understanding of the relationship between diet and health. Also, it was reflected in their purchase intention and purchasing behaviour of food items. Cluster 2 comprising $30.9 \%$ of the respondents had a clear understanding of diet and health but it was not reflected in their purchasing behaviour of food items. Cluster $3(4.6 \%)$ represents the consumers who did not have a clear knowledge about the diet and health and also they do not have any idea about that when they are buying or consuming food products.

Jain et al. (2013) reported that the beliefs about the dietary value and health effects of a food, perhaps is more significant than actual nutritional quality in shaping a person's food choice which also reflected by the current study.
Consumers' knowledge and awareness on healthy dairy products consumption with special reference to FDPs

An important prerequisite for consumers' interest in a specific group of foods as well as the buying and consumption of such foods is the identification of different groups of food (Menrad and Sparke, 2006). In this sense, it is important to know whether the consumers are aware of the concept of FF, especially FDPs and what consumers have in mind in case they know this type of food. Further, the food industry and marketers needs to understand the extent of consumers' awareness and perceptions towards FF because many factors may influence consumers' purchasing decisions (Rezai et al., 2012). Although consumers consume these products, the majority of the consumers (59\%) in the Western Province of Sri Lanka do not have a clear idea or an image about what are those and the term. The concept is still novel to the majority of the consumers. Only $41 \%$ of consumers had knowledge and awareness about FDPs.

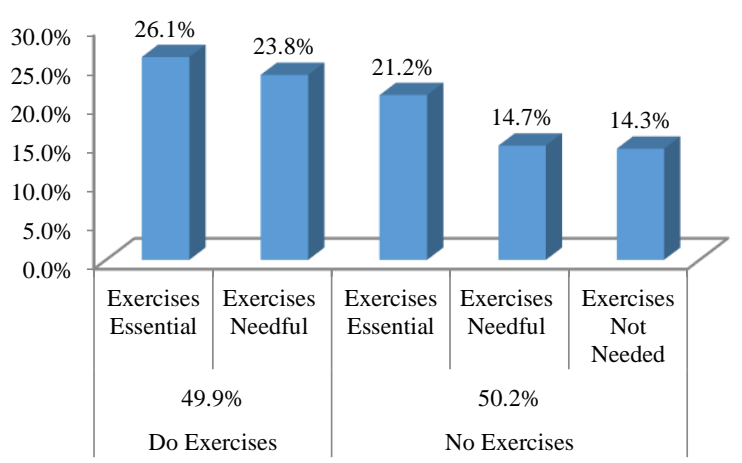

Figure 1. Consumer clusters based on their opinion on doing exercises for a healthy life

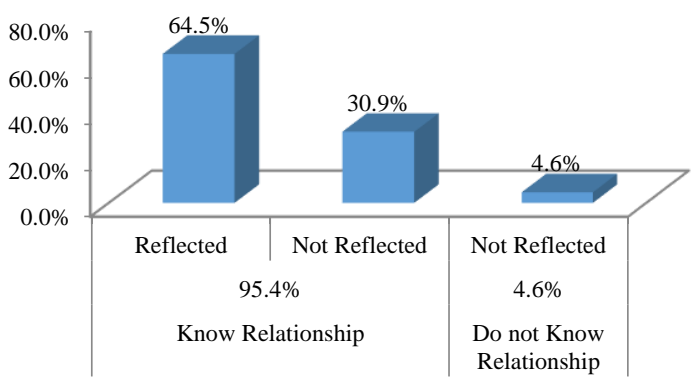

Figure 2. Consumer clusters based on their knowledge on the relationship between diet and health and reflection in buying/consuming food products

In the study conducted in Pakistan, Ali and Rahut (2019) also showed that the Pakistan consumers' knowledge and awareness are limited regarding the FFs. It was reported that only about $20 \%$ of the respondents knew while another $15 \%$ had a little knowledge about the FFs. Also the results indicated that $32 \%$ of the respondents did not know about FFs and the other 33\% had never heard about it. In the study conducted in Italy, Azzurra and Paola (2009) examined the consumers' degree of knowledge on organic and FF and they reported that organic products were more familiar to consumers than FFs. Organic foods 
were known by approximately $45 \%$ of the respondents while functional only by $31 \%$. Vella et al. (2014) reported that increased awareness and knowledge about FFs was the most frequently identified factor that would increase consumption. Therefore, it is important to make consumers aware of FFs and dairy products through various means not only to be succeeded in the current competitive market but also to have a healthy population and a healthy nation.

Among many of the functional ingredients, soy proteins, carotenoids, dietary fibers, omega fatty acids, conjugated linoleic acid, minerals, probiotics, prebiotics, and vitamins are commonly added to develop FFs (IFIC, 2009). However, the majority $(87.9 \%)$ of the consumers did not have an idea about the ingredients available in FFs that are responsible for making consumers healthy. Only a few $(6.2 \%)$ followed by $5.9 \%$ of the consumers mentioned that they moderately know and fully aware of the ingredients added to FFs, respectively. Maintaining desirable body composition and immune health, maintenance of digestion, reducing risk of coronary heart diseases, maintaining eye and bone health, supporting cell growth, helping to regulate metabolism and maintenance of mental functions, supporting blood cell formation, reducing the risk of osteoporosis and helping to regulate calcium and phosphorus are some benefits of FFs including FDPs (Hasler, 2002). However, a majority (70\%) of the consumers did not have a clear idea about the benefits received from consuming FDPs while $10.4 \%$ of the consumers mentioned that they have a moderate understanding while $19.5 \%$ of the consumers fully aware of the benefits received through the consumption of FDPs.

\section{Consumers' Degree of Orientation and Attitude Towards Healthy Dairy Product Consumption}

Preference to buy FDPs and recommendation to the society

The study showed that $(37.8 \%)$ of consumers were willing to buy/consume FDPs and they believe that it is important for better health. However, the majority of the consumers were willing to buy/consume FDPs with a moderate preference. Only $3 \%$ of consumers were not willing to buy FDPs due to different reasons. More than $92 \%$ of the consumers mentioned that they recommend their family members to consume FDPs and only $7.9 \%$ of consumers do not. The majority of the consumers mentioned that they recommend consuming FDPs to the others. It represents $89.5 \%$ of the consumers in the sample while others do not.

Effect of information availability, information sources, trustfulness and media advertising on consumer knowledge of FDPs

Figure 3 shows the different sources used by the consumers to get information about FDPs. The majority of the consumers $(97.7 \%)$ get information through electronic media such as television followed by product labels $(80.8 \%)$. The Wilcoxon signed-rank test showed that the availability of more information regarding FDPs, the trustfulness of information and information sources, available information sources to know about FDPs, media advertising elicit a significant $(\mathrm{p}<0.05)$ change in consumer knowledge.
A study conducted in Turkey by Bilgiç and Yüksel (2012) to find out the university student's perception and attitudes towards FFs, found that television advertisements were the most effective information dissemination source followed by the information gets from the shopping malls while shopping. In the study conducted in Italy by Annunziata and Vecchio (2011) on factors affecting Italian consumers' attitudes towards FFs mentioned that consumers like more details and they consider it necessary to implement information campaigns and public education activities, improve nutritional claims on labels and to introduce a logo that might draw attention to the health benefits of the FFs.

In a study conducted in Canada on FF awareness and perceptions concerning information sources in older adults by Vella et al., 2014 reported that the older adult consumers primarily utilize food labels as a source of information about FFs and they seek more information and prefer to receive information through various sources such as TV commercials, newspapers, magazines, food labels, internet etc. As increased knowledge and awareness is the primary factor that would increase FF consumption, information coming from these sources is likely to influence awareness and consumption.

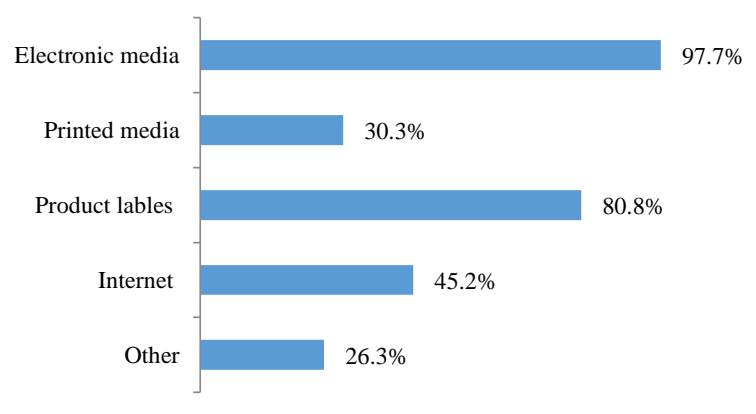

Figure 3. Information sources on FDPs accessed by consumers

\section{Inferences for the Marketing/Processing Industry for Popularization of FDPs in The Country}

Consumer preference for dairy products to be developed as future FFs

According to the results of the survey, powder milk achieved the highest demand $(94.5 \%)$ followed by ice cream $(91.2 \%)$, yogurt $(89.2 \%)$, liquid milk $(81.3 \%)$, cheese $(78.1 \%)$, butter $(68.4 \%)$ and drinking yogurt $(37.4 \%)$ by the consumers to be developed as future FDPs. However, this figure might not apply to the other nations because Sri Lankans addicted to powdered milk consumption than other milk products.

Market access to FDPs by the consumers

The study showed that the majority $(42 \%)$ of the consumers buy FDPs through super market chain, which might be due to the availability of a large collection of dairy products and variations followed by groceries $(30.3 \%)$ and small shops $(25.1 \%)$. Farm outlets showed the minimum access $(2.6 \%)$ to the FDPs. Normally, what is available in farm outlets are raw, minimally processed products that are transported to factories for further processing. 
Consumer's opinion regarding market price and market availability of FDPs

According to the results, a majority $(55.4 \%)$ of the consumers did not have an idea about the market prices of FDPs available and $34.5 \%$ of consumers said that market price is high for all the FDPs. Only $10.1 \%$ of consumers mentioned that the market price is acceptable and comparable to the other dairy products. The majority of the consumers did not satisfy with the market availability of FDPs. They mentioned that the product availability and the variability are poor. However, $21 \%$ of the consumers satisfied with the market availability of FDPs.

The association between demographic variables and consumer tendency towards a healthy lifestyle and their knowledge and awareness on FDPs

According to Pearson's Chi-square test statistics results, the age of the consumers showed a significant $(\chi 2=19.41, \mathrm{P}<0.05)$ and a positive association with a tendency towards a healthy lifestyle. The demographic factors such as gender, age, civil status, occupation, the income of the consumers are independent with the consumers' knowledge and awareness on FDPs. However, the education level of the consumers showed a significant association with knowledge and awareness $(\chi 2=21.27$; $\mathrm{P}<0.05)$. Further, Pearson's Chi-square test indicated that there was a significant association between the education level of the consumer and the knowledge of the ingredients present in FFs $(\chi 2=17.54 ; \mathrm{P}<0.05)$.

\section{Conclusion}

Empirical findings showed that the majority of the consumers in the Western Province of Sri Lanka considered taste and cost rather than health and nutrition in food choices, even though it has been reported that the leading cause of death among Sri Lankans is due to NCDs. It has been found that the concept of "functional food" is still novel to the consumers. The age of the consumers showed a significant $(\chi 2=19.41, \mathrm{P}<0.05)$ and a positive association with a tendency towards a healthy lifestyle. The education level of the consumers showed a significant positive association with the knowledge and awareness of FDPs $(\chi 2=21.27 ; \mathrm{P}<0.05)$ as well as the knowledge of the ingredients present in FFs $(\chi 2=17.54 ; \mathrm{P}<0.05)$. The majority of consumers have a positive opinion regarding FDPs and they like to direct others to consume those products. Information availability, trustfulness, and media advertising have a significant $(\mathrm{P}<0.05)$ effect on increasing consumer knowledge on FDPs. Powdered milk, ice-cream products and yoghurt have a considerable demand among consumers to be developed as future FDPs. Since the majority of the consumers did not satisfy with the existing market access and availability of variants, a good potential exists for the introduction of novel FDPs to the FF market of Sri Lanka.

\section{References}

Ali A, Rahut DB. 2019. Healthy foods as proxy for functional foods: Consumers' awareness, perception and demand for natural functional foods in Pakistan. Hindawi-Int $\mathrm{J}$ of Food Sci, 1-12. doi.org/10.1155/2019/6390650

Annunziata A, Vecchio R. 2011. Factors affecting Italian consumers attitudes towards functional foods. AgBioForum, 14 (1): $20-32$
Ares G, Gambaro A. 2007. Influence of gender, age and motives underlying food choice on perceived healthiness and willingness to try functional foods. Appetite, 49, 148-158. doi:10.1016/j.appet.2007.01.006

Azzurra A, Paola P. 2009. Consumers' behaviours and attitudes toward healthy food products: The case of Organic and Functional foods. $113^{\text {th }}$ EAAE Seminar "A resilient European food industry and food chain in a challenging world", Chania, Crete, Greece, September 3 - 6.

Bilgiç S, Yüksel A. 2012. University Students' Perception and Attitudes towards Functional Foods in Istanbul. Proceedings of the 2012 International Conference on Industrial Engineering and Operations Management Istanbul, Turkey, July $3-6,1127-1137$

Department of Census and Statistics. 2011. Population by religion according to districts, 2012. Census of Population \& Housing. Department of Census \& Statistics, Sri Lanka.

Gasmalla MAA, Tessema HA, Salaheldin A, Alahmad K, Hassanin HAM, Aboshora W. 2017. Health benefits of milk and functional dairy products. MOJ Food Process Technol. 4(4): 108-111

Grand View Research. 2019. Functional Foods Market Size, Share \& Trends Analysis Report By Ingredient (Carotenoids, Prebiotics \& Probiotics, Fatty Acids, Dietary Fibers), By Product, By Application, And Segment Forecasts, 2019-2025. Market Research Report, Grand View Research, April, 2019. https://www.grandviewresearch.com/industry-analysis/ functional-food-market. Accessed on 25/06/2019

Hasler CM. 2002. Functional Foods: Benefits, Concerns and Challenges-A position paper from the American Council on Science and Health. J Nutr., 132: 3772-3781 DOI:10.1093 /jn/132.12.3772

Hasler CM, Brown AC. 2009. Position of the American Dietetic Association: Functional Foods. J of the American Dietetic Association. 109(4), 735-746 DOI:

10.1016/j.jada.2009.02.023

IFIC 2009. Functional Foods Component Chart: http://www.ific.org/nutrition/functional/index.cfm. Accessed on $26 / 06 / 2019$

IFIC 2011. IFIC functional foods/ Foods for health media resources. International Food Information Council. https://foodinsight.org/ific-functional-foods-foods-forhealth-media-resources/. Accessed on 02/07/2019.

IFT 2017. Functional Foods. Institute of Food Technologists. Chicago, IL. http://www.ift.org/knowledge-center/focusareas/food-health-and-nutrition/ functional -foods. aspx. Accessed on 2/7/2019

Jain S, Sharma K, Khadke M. 2013. Consumer behavior towards functional foods in India-A study of market drivers and challenges. IOSR Journal of Business and Management (IOSR-JBM). PP 33-40

Jayasuriya NA. 2016. Sri Lankan Consumer attitudes towards healthy meals. J of Marketing and Consumer Research. 24: 69-79

Jayawardena S. 2018. NCDs the reason behind 75\% deaths in Sri Lanka. Daily FT-e Paper. http://www.ft.lk/healthcare/NCDsthe-reason-behind-75-deaths-in-Sri-Lanka/45-649439. Accessed on 10-05-2019.

Kendilci EA, Kendilci K, Gunes G. 2017. Assessment of awareness, knowledge levels and consumer perception of students of health high school towards functional foods. Med Science. 1-9 doi: 10.5455/medscience.2017.06.8694.

Menrad K. 2003. Market and marketing of functional food in Europe. Journal of Food Engineering, 56, 181-188.

Menrad K, Sparke K. 2006. Consumers' attitudes and expectations concerning functional food. University of Applied Sciences of Weihenstephan, Science Centre Straubing, Schulgasse 18, 94315 Straubing, Germany.

Mohamad SS, Rusdhi SD, Hashim NH. 2014. Organic food consumption among urban consumers: Preliminary results. Procedia-Social and Behavioral Sciences. 130, 509-514. 
Naughton P, McCarthy SN, McCarthy MB. 2015. The creation of a healthy eating mortivation score and its association with food choice and physical activity in a cross sectional sample of Irish adults. International Journal of Behavioral Nutrition and Physical Activity (2015) 12:74 DOI 10.1186/s12966015-0234-0

Rezai G, Teng PK, Mohamed Z and Shamsudin MN. 2012. Functional Food Knowledge and Perceptions among Young Consumers in Malaysia, World Academy of Science, Engineering and Technology, International Journal of Economics and Management Engineering Vol:6, No:3, pp $307-311$.

Roberfroid MB. 2002. Global view on functional foods: European perspectives. British Journal of Nutrition, 88, S133-S138. DOI: 10.1079/BJN2002677
Siro I, Kapolna E, Kapolna B, Lugasi A. 2008. Functional food. Product development, marketing and consumer acceptance-A review. Appetite, 51, 456-467. DOI: 10.1016/j.appet. 2008.05.060

Vella MN, Stratton LM, Sheeshka J, Duncan AM. 2014. Functional food awareness and perceptions in relation to information sources in older adults. Nutrition Journal, 13:44. doi:10.1016/j.appet.2008.05.060

World Cancer Research Fund / American Institute for Cancer Research. 2007. Food, Nutrition, Physical Activity, and the Prevention of Cancer: a Global Perspective, Washington DC, ISBN: 978-0-9722522-2-5, pp 5- 14.

World Health Organization. 2015. "World report on ageing and health 2015", Available at: http://www.who.int/ageing /events/world-report-2015-launch/en. Accessed on 5/7/2019 